\title{
Towards treating lupus nephritis without oral steroids: a dream-come-true?
}

\section{Frédéric A Houssiau, ${ }^{1}$ David Isenberg ${ }^{2}$}

The discovery in the late 1940s of the very potent anti-inflammatory and immunosuppressive properties of glucocorticoids (GC) ${ }^{1}$ has dramatically improved the prognosis of severe systemic lupus erythematosus (SLE), with survival rates increasing markedly from $50 \%$ at 3 years in $1953^{2}$ to $92 \%$ at 10 years in recent series. ${ }^{3}$ In particular, intravenous pulse methylprednisolone (MP) therapy, introduced as treatment for severe lupus manifestations in the 1970s, ${ }^{4}$ displays remarkable and prompt beneficial effects in acutely ill SLE patients suffering from renal impairment, central nervous system disease, arthritis, pleuropericarditis, fever or severe thrombocytopenia. ${ }^{5}{ }^{6}$ Unfortunately, many patients, especially those taking $>7.5 \mathrm{mg}$ per day for long periods, experience the serious consequences of GC therapy, such as, increased risk of infection, avascular osteonecrosis, osteoporosis, myopathy, diabetes mellitus or Cushingoid features, as well as skin bruising and cataracts. Most of these side effects impact upon a patient's body image, being a huge source of emotional distress in young (sometimes teenaged) female patients, who are the principle victims of SLE.

Several longitudinal studies performed in SLE patients have revealed that GCs are the main cause of damage, as determined by the Systemic Lupus International Collaborating Clinics (SLICC)/ American College of Rheumatology (ACR) damage index (DI). ${ }^{7}$ Thus, the mean DI rose from 0.33 at baseline to 1.9 after 15 years of follow-up in an inception cohort, and damage was considered as definitely GC-related in $16 \%$ and $49 \%$ of the cases at baseline and last

\footnotetext{
${ }^{1}$ Pôle et Service de Rhumatologie, Institut de Recherche Expérimentale et Clinique, Cliniques Universitaires Saint-Luc, Université catholique de Louvain, Brussels, Belgium

${ }^{2}$ Division of Medicine, Centre for Rheumatology, University College London, London, UK
}

Correspondence to Professor Frédéric A Houssiau, Department Rheumatology, Saint-Luc University Hospital, UCL 5390, Avenue Hippocrate 10, B-1200 Bruxelles, Belgium;frederic.houssiau@uclouvain.be follow-up, respectively. ${ }^{8}$ In another series of incident cases, the accrual of organ damage was found to correlate with the mean daily prednisone dose, with the risk increasing for doses higher than $6 \mathrm{mg}$ per day. ${ }^{9}$ Finally, damage accrual was found to be associated with higher risk of mortality, every 1-point increase in DI being associated with a 1.32 times more risk to die during follow-up. ${ }^{10}$ These data reinforce the concerns of both physicians and patients about the use of GCs.

In order to limit GC toxicity, lower oral doses of GCs have been successfully used in lupus nephritis (LN) trials, ${ }^{11}$ and other immunosuppressants, such as azathioprine, cyclosporin mycophenolate (MMF) or cyclophosphamide, are now widely used as steroid-sparing agents. Most of the now 'traditional' immunosuppressant drugs have been available for more than 25 years. However, the availability of biologic agents, notably rituximab (RTX) which was first used to treat SLE over a decade ago, ${ }^{12}$ now offers the prospect of an alternative steroid-sparing regime. ${ }^{13}$ But the step taken by the nephrologists of the Imperial College in London, is bold and potentially 'game changing'. They report a series of $50 \mathrm{LN}$ patients treated without any oral GC. ${ }^{14}$ Patients were given two pulses of $500 \mathrm{mg}$ $\mathrm{MP}$ and two doses of $1 \mathrm{~g}$ RTX, both 2 weeks apart, in addition to MMF at a daily dose of $1-3 \mathrm{~g}$, the latter monitored according to mycophenolic acid titres. Complete renal remission, defined by a urine protein/creatinine ratio $<50 \mathrm{mg} /$ $\mathrm{mmol}$ and a serum creatinine no greater than $15 \%$ above baseline, was achieved in $52 \%$ of the patients at 1 year, without worrying toxicity signals.

The authors must be congratulated for their idea, inspired by recent achievements in transplantation medicine, to avoid the use of a drug that has been the first choice in the treatment of LN for 60 years. Should this approach be validated in a controlled trial, their contribution would be a milestone in the saga of LN treatment. However, although this paper will excite much enthusiasm, in particular in patients, several caveats need to raised. The results have been obtained in an open study rather than a double-blind controlled trial. In its defence, the hard data gathered when studying renal lupus do provide some reassurance. In this respect, a randomised non-inferiority open multicenter trial, entitled RITUXILUP, is planned to commence later this year. Both groups of $\mathrm{LN}$ patients will receive two pulses of $\mathrm{MP}$ $500 \mathrm{mg}$ and MMF, patients from the control group will receive additional oral GC therapy (starting at $0.5 \mathrm{mg} / \mathrm{kg} / \mathrm{d}$ ), and patients from the experimental group will be given two doses of RTX $1 \mathrm{~g}$. The hope is that both groups will have similar renal response rates, with less toxicity in the patients given RTX instead of a standard oral GC regimen. It is also to be hoped that this trial will avoid the pitfalls of the failed LUNAR trial ${ }^{15}$ which did not seek to recruit refractory to standard-of-care patients, and in which the median duration from diagnosis to study inclusion was poorly matched (5.4 months for the placebo-treated patients vs 11.1 months for those given RTX). In addition, much higher doses of prednisolone $(0.75 \mathrm{mg} /$ $\mathrm{kgm}$ ) were used in all patients which might have blunted the ability of RTX to show beneficial effects.

Some other issues need to be considered. For example, $44 \%$ of patients had pure membranous International Society of Nephrology (ISN)/Renal Pathology Society (RPS) Class V LN, a figure much higher than in most series. One-third of patients had normal serum complement levels and no anti-DNA $\mathrm{Ab}$, a finding likely to be related to over-representation of Class $\mathrm{V}$ LN and, again, uncommon in most other studies. Last, but not least, relatively few patients were recorded to have had extrarenal symptoms, such as cutaneous and musculoskeletal manifestations which were observed in less than one-third of the cases. These are the most common lupus symptoms. Taken together, a central question is whether the good results obtained in this single-center LN population, with a strong renal referral bias, can be extrapolated to a more general lupus population in which LN is generally accompanied by many systemic features, that most often require and respond to courses of oral GC. The answer to this pivotal question will depend on the ability of RTX, together with $M M F$, to reduce non-renal disease manifestations. This was not demonstrated in the EXPLORER trial, ${ }^{16}$ in which RTX was prescribed as an add-on therapy superimposed to high doses of GC. However, many concerns have been 
expressed about the study design (reviewed in 17) of that trial. In addition, albeit in open-label studies, there are many reports of the broad utility of RTX. ${ }^{17}$

Future studies will be needed to address the following unanswered questions. Will RTX retreatment be needed, and when, a central issue as Condon et $a l^{18}$ report a relatively high renal relapse rate $(21 \%$ after a median time of 65 weeks), and as renal relapses contribute to poor long-term renal outcome? Will a steroid-free approach reduce damage accrual? Will a patient's quality of life improve? Will the cost of RTX treatment be compensated by savings due to decreased GC-induced damage? It is tantalising to answer these questions positively, but only time and good clinical science will tell. Let us travel in hope!

Contributors Both FAH and DI wrote the editorial together.

Competing interests None.

Provenance and peer review Commissioned; externally peer reviewed.

Accepted 8 April 2013

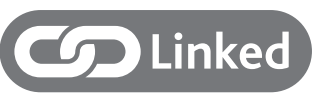

- http://dx.doi.org/10.1136/annrheumdis-2012-202844
Ann Rheum Dis 2013;72:1271-1272.

doi:10.1136/annrheumdis-2013-203205

\section{REFERENCES}

1. Hench PS, Kendall EC, Slocomb CB, et al. Effect of hormone of adrenal cortex (17—hydroxyl 11 de-hydro corticosterone:compound $\mathrm{E}$ ) and of pituitary adrenocorticotropic hormone on rheumatoid arthritis: preliminary report. Proc Mayo Clin 1949;13: 181-2.

2. Jessar RA, Lamont-Havers RW, Ragan C. Natural history of lupus erythematosus disseminatus. Ann Intern Med 1953;38:717-31.

3. Cervera R, Khamashta MA, Font J, et al. Morbidity and mortality in systemic lupus erythematosus during a 10-year period: a comparison of early and late manifestations in a cohort of 1,000 patients. Medicine 2003;82:299.

4. Cathcart ES, Idelson BA, Scheinberg MA, et al. Beneficial effect of methylprednisolone "pulse" therapy in diffuse proliferative lupus nephritis. Lancet 1976;1:163-6.

5. Isenberg DA, Morrow WJW, Snaith ML. Methyl prednisolone pulse therapy in the treatment of systemic lupus erythematosus. Ann Rheum Dis 1982;41:347-51.

6. Chatham WW, Kimberly RP. Treatment of lupus with corticosteroids. Lupus 2001;10:140-7.

7. Gladman DD, Ginzler E, Goldsmith C, et al. The development and initial validation of the Systemic Lupus International Collaborating Clinics/American College of Rheumatology damage index for systemic lupus erythematosus. Arthritis Rheum 1996;39:363-9

8. Gladman DD, Urowitz MB, Rahman P, et al. Accrual of organ damage over time in patients with systemic lupus erythematosus. J Rheumatol 2003;30:1955-9.

9. Thamer M, Hernan MA, Zhang $Y$, et al. Prednisone, lupus activity, and permanent organ damage. J Rheum 2009;36:560-4.
10. Chambers SA, Allen E, Rahman A, et al. Damage and mortality in a group of British patients with systemic lupus erythematosus followed up for over 10 years. Rheumatology 2009;48:673-5.

11. Houssiau FA, Vasconcelos C, D'Cruz D, et al. Immunosuppressive therapy in lupus nephritis: the Euro-Lupus Nephritis Trial, a randomized trial of low-dose versus high-dose intravenous cyclophosphamide. Arthritis Rheum 2002;46 2121-31.

12. Leandro MJ, Edwards JC, Cambridge G, et al. An open study of B lymphocyte depletion in systemic lupus erythematosus. 2002;46:2673-7.

13. Ezeonyeji AN, Isenberg DA. Early treatment with rituximab in newly diagnosed systemic lupus erythematosus patients: a steroid-sparing regimen. Rheumatology 2012;51:476-81.

14. Lightstone L, Condon M, Ashby D, et al. Prospective observational single centre cohort study to evaluate the effectiveness of treating lupus nephritis with rituximab and mycophenolate mofetil but no oral steroids. Ann Rheum Dis 2013;72:1280-6.

15. Rovin BH, Furie R, Latinis $K$, et al. Efficacy and safety of rituximab in patients with active proliferative lupus nephritis: the Lupus Nephritis Assessment with Rituximab study. Arthritis Rheum 2012;64:1215-26.

16. Merrill JT, Neuwelt CM, Wallace DJ, et al. Efficacy and safety of rituximab in moderately-to-severely active systemic lupus erythematosus: the randomized, double-blind, phase II/III systemic lupus erythematosus evaluation of rituximab trial. Arthritis Rheum 2010;62:222-33.

17. Furtado J, Isenberg DA. B cell elimination in systemic lupus erythematosus. Clin Immunol 2012;146:90-103.

18. Condon MB, Ashby D, Pepper RJ, et al. Prospective observational single-centre cohort study to evaluate the effectiveness of treating lupus nephritis with rituximab and mycophenolate mofetil but no oral steroids. Ann Rheum Dis 2013:72:1280-6. 